\title{
Descended Mouth Corner: An Ignored but Needed Feature of Facial Rejuvenation
}

\author{
Pedro Vidal ${ }^{1,2,3}$, Juan Enrique Berner ${ }^{2}$, Pablo Castillo ${ }^{2}$, Günther Rochefort ${ }^{2}$, Rodrigo Loubies ${ }^{3}$ \\ ${ }^{1}$ Department of Plastic Surgery, Pontificia Universidad Católica de Chile, Santiago; ${ }^{2}$ Department of Plastic Surgery, Hospital de la Fuerza \\ Aérea de Chile, Santiago; ${ }^{3}$ Cienmanos Foundation, Chile
}

For years, the gold standard in facial rejuvenation has been the face lift. However, exploring new, less complex procedures for achieving the same goal is currently drawing interest. Rejuvenation of the perioral area is a difficult task for plastic surgeons because of the minimal effect that face lift procedures have over this region and the lack of published material on the subject. In this article, the descended mouth corner anguloplasty technique is presented. It is a 20-minutes lift technique that can correct this typical feature of the ageing mouth. The authors have treated 71 patients using the technique with consistently good results, with just one requiring revision. They conclude that this procedure by itself and in combination with other small operations or even a full face lift can rejuvenate the ageing face.

Keywords Surgery, plastic / Rhytidoplasty / Lip / Lifting / Rejuvenation
Correspondence: Pedro Vidal Department of Plastic Surgery, Pontificia Universidad Católica de Chile, Lo Fontecilla 101 Of. 412, Santiago, Chile

Tel: +562-2207-1125

E-mail: pvidalg@mac.com

Presented at the Reunión Mensual Sociedad Chilena de Cirugia Plástica (Monthly Meeting of the Chilean Society of Plastic Surgery) June 18, 2009 in Santiago, Chile.

No potential conflict of interest relevant to this article was reported.

\section{INTRODUCTION}

For many years the gold standard for facial rejuvenation has been the face lift. However, during the last 10 years, requests for less aggressive procedures have been increasing. This is probably related to the long postoperative period and swelling caused by facial lifting and the patients' need to return early to work [1].

Another fact that has pushed many patients to seek alternative procedures are the frequently seen undesired stigma of face lifts.

The evidence of these facts is the enormous increase in "lesser" procedures [2], including those called "lunch hour injections." From the surgeon's point of view, a face lift is a long, tiring procedure, and is frequently followed by complaints from the patients. Therefore, Botox injections, fillers, microdermabrasion, and lasers are becoming alternatives to major surgical interventions.
In response to these issues, some surgeons have designed procedures to comply with patient's requests. There are those that prefer combining several small procedures and obtain surprisingly good results $[3,4]$, perfectly comparable to a face lift.

Rejuvenation of the perioral area has been always a difficult task; among the difficulties encountered are superior lip vertical lines, thin lips, a lowered corner of the mouth, deepening of the nasogenian grooves, and marionette lines. Typically, face lifting procedures do not usually address these factors, although the mouth and lips, being a particularly sensitive area, are a constant concern for middle aged and elderly patients.

In addition to affecting the normal smile, this area is, unfortunately, one of the first to show signs of ageing, such as upper lip descent and lengthening, loss of bony support, elasticity and skin turgor-all features of young and healthy faces.

This article reports on an original technique, adapted from

Copyright $\odot 2013$ The Korean Society of Plastic and Reconstructive Surgeons

This is an Open Access article distributed under the terms of the Creative Commons Attribution Non-Commercial License (http://creativecommons.org/

licenses/by-nc/3.0/) which permits unrestricted non-commercial use, distribution, and reproduction in any medium, provided the original work is properly cited.

www.e-aps.org 


\section{Fig. 1. The "sad" mouth}

One of the main characteristics of the ageing mouth is its sad appearance due to descended corners.

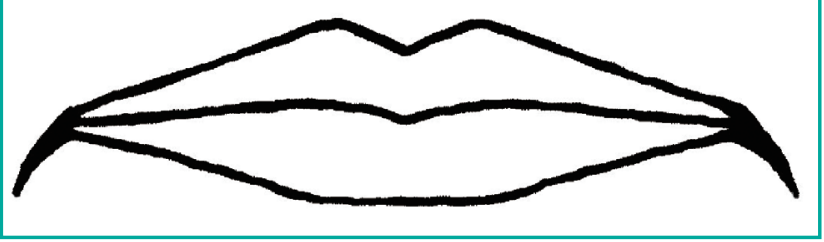

Flowers and Ceydeli [5] that focuses specifically on those patients who request a modification of a sad mouth appearance and on the elderly. We called this expression "sad mouth", and can be used for the cases in which the outer angles of the mouth descend in an inverted $U$, giving patients a non-aesthetic appearance (Fig. 1).

When a person smiles, the risorius, lip levators and zygomaticus major muscles pull the corner of the mouth upwards, resulting in a smiling face. In some older people, the smile becomes a conscious, tiring, and sometimes forced expression, which is uncomfortable in social situations, particularly with their relatives and partners. A typical comment from these patients is: "I am tired of saying to everybody that I am not annoyed or sad."

Procedures that attempt to correct the "sad mouth" include weakening of the depressor anguli oris muscle through botulinum toxin injections, which has little effect and requires a very skilled physician to obtain a discrete elevation [6]. Other procedures include superficial musculoaponeurotic system plication above the angle during a full facelift, and a procedure designed by Marinetti [7] and popularized by Little, consisting of intraoral mucosa resection, with or without suturing the upper muscles. We have a particular interest in this topic and have tried every alternative, with unsuccessful outcomes in the long term $[8-10]$.

\section{IDEA}

One of us was shown the descended mouth corner anguloplasty technique by Dr. Robert Flowers, of Honolulu, Hawaii, some years ago. This co-author was impressed with the immediate result and started using it. It is an extremely simple procedure that can be done under local or general anesthesia, alone or as part of several rejuvenation procedures. The whole procedure takes less than 10 minutes on each side.

Before starting, a double triangle is designed over the upper lateral aspect of the mouth: going from the vermillion border upward and laterally, as shown in Fig. 2. We start marking an initial 20-mm line following the vermillion border; we then mark
Fig. 2. Skin marking of the descended mouth corner anguloplasty

The cornerstone of this procedure is correct skin marking before the incision. The first line follows the vermillion border $20 \mathrm{~mm}$. Then two superimposed triangles are drawn sharing the initial line as their base.

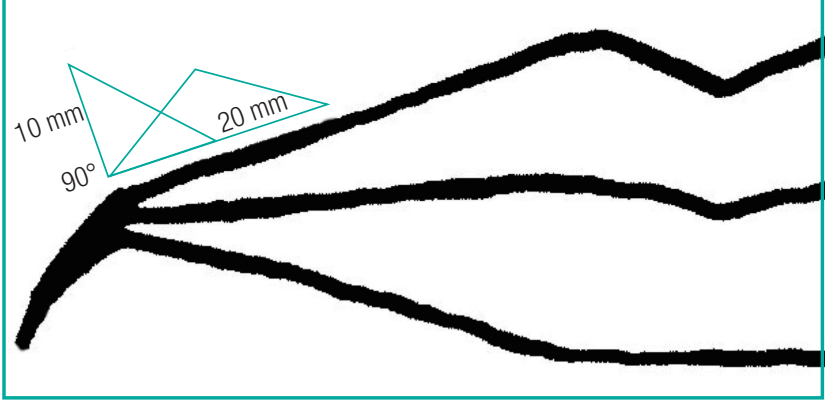

a perpendicular $10-\mathrm{mm}$ line at the lateral end of the vermillion border. A third line completes the first right-angled triangle over which a second scalene triangle is marked using the line above the vermillion border as its base.

A full thickness skin resection of the limits of these 2 triangles is then performed, comprising less than $1 \mathrm{~cm}^{2}$. When it is closed, a significant advance upwards and slightly laterally is produced by putting the first stitch between the upper medial notch and the lower lateral corner of the incision. The closure is carefully done in two planes; the skin stitches are removed at day 5 or 6 . Scar care is the same as with any facial scar. All of the patients are advised to use sun-blocking creams during the first two months.

This technique resembles the lip lift proposed by Austin and Weston [11] in which an oval-shaped skin resection is made above the vermillion border. In our experience this approach is suboptimal because does not correct the descended mouth corner because instead of lifting the angle it pulls the angle laterally, producing a larger scar [12].

So far, over a period of four years we have done this procedure in 71 patients, as a single procedure or part of several surgical operations. The patients included 55 females and 16 males between 40 and 83 years of age. Just 5 patients had this procedure as a single procedure, all women, and the rest in combination with a face lift, blepharoplasty, or rhinoplasty (Fig. 3).

All of the patients were satisfied or happy with the result. All of them expressed that if given the opportunity again, they would undergo the same surgery. At least half of the men did mention that the scar was more visible than expected during the first month; however, it became attenuated after 8 weeks. For females, it is easier to cover the scar with lipstick, and thus they had no complaints. We discourage this procedure in patients with a keloid or hypertrophic scar history.

We performed one small scar revision in one female patient for 


\section{Fig. 3. Three patients before and after surgery}

$(A, B)$ were taken before and 6 months after the procedure in a 48-year-old female patient and $(C, D)$ also show the result in a 52 -year-old female patient before and 6 months after the descended mouth corner anguloplasty.
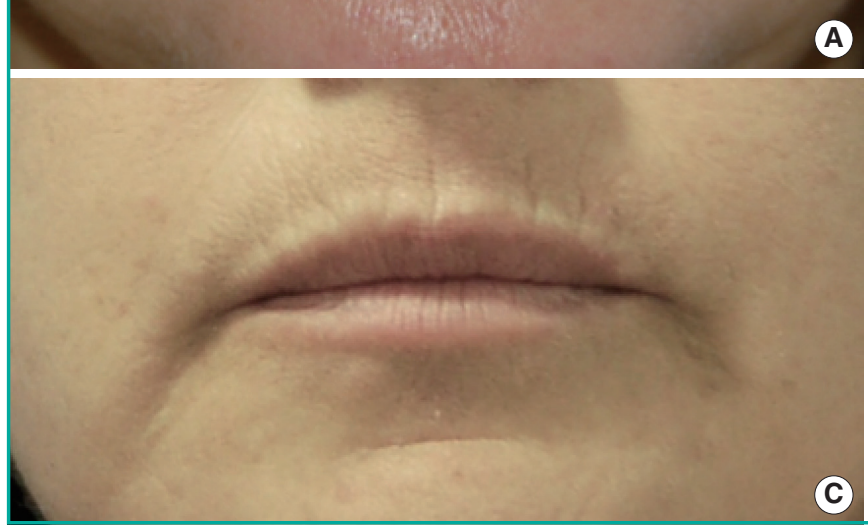

asymmetry. There were no hypertrophic or keloid scars following this procedure, and the patients reported satisfaction after revision. We have not seen any other intraoperative or postoperative complications of the technique proposed in this article.

\section{DISCUSSION}

Within our medical practice, the descended mouth corner anguloplasty has become a routine procedure in facial rejuvenation patients. It is an easy, fast operation, and the learning curve is short. In our opinion, it should be considered an excellent ancillary element for certain patients, as part of those several small procedures that add up to a better facial appearance, together with the use of autologous fat, with or without a face lift, or with blepharoplasty. We have seen the best results when combined with a very slight lip and nasogenial fat injection. All patients should be warned about the possibility of unsightly scars.

\section{REFERENCES}

1. Marcus BC. Rhytidectomy: current concepts, controversies and the state of the art. Curr Opin Otolaryngol Head Neck Surg 2012;20:262-6.

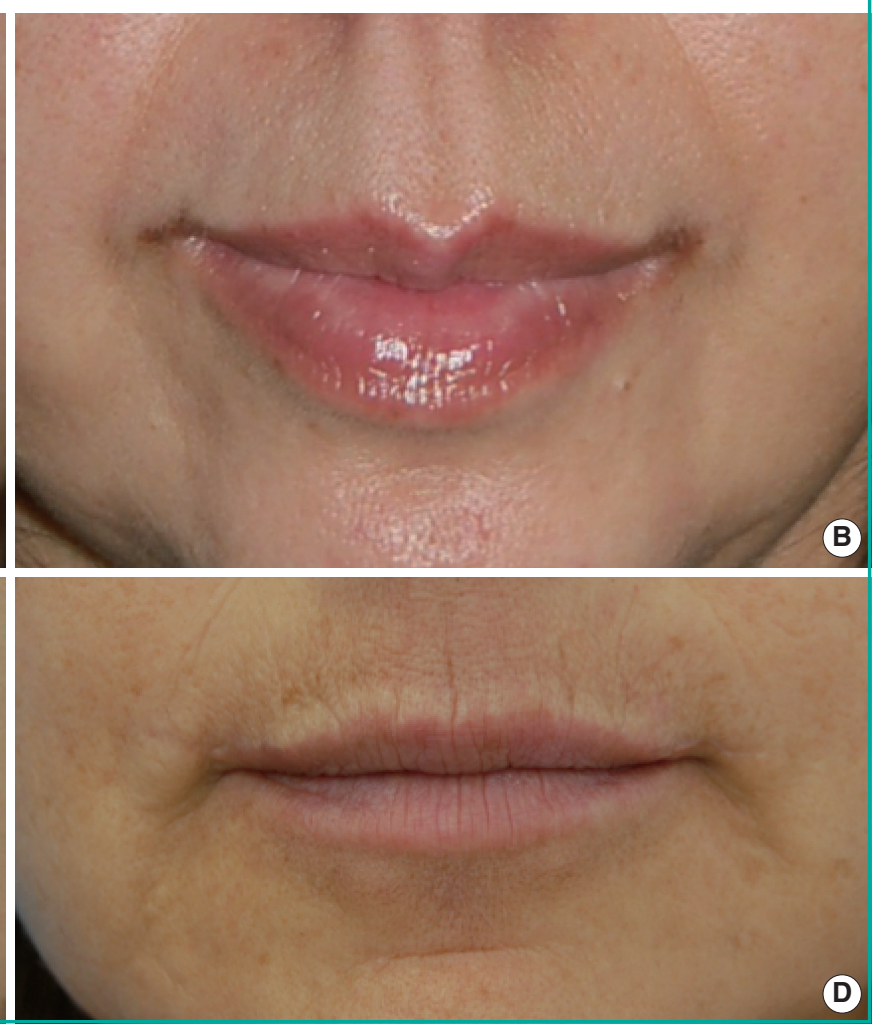

2. International Society of Aesthetic Plastic Surgery (ISAPS). International Survey on Aesthetic/Cosmetic Procedures Performed in 2009 [Internet]. Hanover, NH: ISAPS; c2013 [cited 2013 Sep 25]. Available from: http://www.isaps.org/ files/html-contents/Methodology_ISAPS_Survey2009.pdf.

3. Flowers RS, Ceydeli A. Mag-5: a magnificent approach to upper and midfacial “magic". Clin Plast Surg 2008;35:489-515.

4. Nguyen AT, Ahmad J, Fagien S, et al. Cosmetic medicine: facial resurfacing and injectables. Plast Reconstr Surg 2012; 129:142e-153e.

5. Flowers RS. Course \#708 Peri-oral wizardry 2009: more simple operations that restore youthfulness and correct deformity in the mouth area. In: The Aesthetic Meeting 2009; 2009 May 2-7; Las Vegas, NV.

6. Goldman A, Wollina U. Elevation of the corner of the mouth using botulinum toxin type a. J Cutan Aesthet Surg 2010; 3:145-50.

7. Marinetti CJ. The lower muscular balance of the face used to lift labial commissures. Plast Reconstr Surg 1999;104:115362.

8. Perkins NW, Smith SP Jr, Williams EF 3rd. Perioral rejuvenation: complementary techniques and procedures. Facial Plast Surg Clin North Am 2007; 15:423-32. 
9. Perkins SW. The corner of the mouth lift and management of the oral commissure grooves. Facial Plast Surg Clin North Am 2007;15:471-6.

10. Weston GW, Poindexter BD, Sigal RK, et al. Lifting lips: 28 years of experience using the direct excision approach to reju- venating the aging mouth. Aesthet Surg J 2009;29:83-6.

11. Austin HW, Weston GW. Rejuvenation of the aging mouth. Clin Plast Surg 1992;19:511-24.

12. Panfilov DE. Aesthetic surgery of the facial mosaic. New York Springer; 2007. 